\title{
Resistências no mundo capitalista atual: da desesperança à produção de vida
}

\section{COMITÊ INVISÍVEL}

Motim e destituiçáo agora

Tradução de Vinicius Honesko

São Paulo: N-1 Ediçóes, 2017.

\section{| ${ }^{1}$ Luiz Gustavo Duarte I}

1 Centro de Ciências da Saúde (Mestrado), Universidade Estadual de Londrina. Londrina-PR, Brasil (guto.luizduarte@gmail.com). ORCID 0000-0003-3196-5174

Recebido em: 03/07/2019

Aprovado em: 20/09/2019

Revisado em: 21/01/2020

DOI: http://dx.doi.org/10.1590/S0103-73312020300121

Escrito pelo Comitê Invisível, grupo originário da França formado por um conjunto de autores anônimos, o livro é composto de seis capítulos interdependentes que formam uma malha de deslocamentos, que abrange desde os costumes cooptados pelo capitalismo até a organização da resistência em si. Nessa trajetória, algumas questôes levantadas em escritos anteriores, como "A insurreiçáo que vem" (COMITÊ INVISÍVEL, 2013), são revisitadas, de modo que as discussões prévias permaneçam em evidência, mas ganhando um novo fôlego e aprofundamentos em outros segmentos.

O primeiro capítulo, intitulado "O amanhã está anulado", inicia uma instigante leitura que nos traz reflexóes sobre os possíveis caminhos para seguirmos diante do futuro distópico anunciado pelo nosso presente. Para isso, a passividade assumida por nós em diferentes contextos é colocada em questáo, de modo que as situaçóes bizarras e humilhantes que ocorrem em nosso cotidiano são assistidas como um espetáculo (de um naufrágio) observado de longe por espectadores em um mundo que está repleto de críticas e superinformaçôes sobre qualquer assunto, sem no entanto desencadear uma ação. Um elemento importante nesse deslocamento é a linguagem utilizada atualmente pelos veículos de comunicação, governos, internet, 
entre outros, que nos inunda e traveste as coisas diante das suas contradiçóes, como guerras pela paz e sistemas de vigilância disseminados como dispositivos de segurança. Nesse jogo da linguagem, o que fica é a convocatória de que precisamos fazer outro uso dela, falando a partir da vida, das situaçóes, do mundo, com uma outra ideia de verdade e outra ideia de mentira.

A noção de verdade nesse momento aparece como elemento construído por meio da linguagem que vai diretamente influenciar nossas percepçôes e a forma como nos relacionamos com o mundo que nos cerca. Dessas percepçóes, desse contato sem intermédios com o mundo, existe a possibilidade de novas relaçóes e movimentos serem constituídos, podendo ser apresentados na forma do motim, o qual opera na busca de laços vivos e irreversíveis, sem esperança, gerados na formação franca de amizades e agires. Nesse caminho, os autores citam a jornada insurrecional de Viena de 1927 como exemplo de como o motim age, permitindo fazer ver o que não é enxergado naturalmente pela sociedade (com suas amarras e distanciamentos pelos paradoxos, linguagens ou imagens).

No segundo capítulo, a discussão de um mundo fragmentado é posta com o capitalismo entendido como direcionador da construção desse tipo de mundo, seja na sociedade, na ciência ou no trabalho. A ideia de unicidade é tida como ficção; ela pode ter sido eficaz em certos momentos históricos, para construção de forças sociais, por exemplo, mas atualmente não consegue ter a mesma capacidade unificadora. É um momento em que as singularidades se levam a si mesmas; o "interesse de todos" já não tem mais lugar. Essa situação é exemplificada pela Cúpula de Copenhague em 2009, quando a unificação em torno de um problema gerou um verdadeiro sentimento de "salve-se quem puder".

Essa unidade ficcional, chamada politicamente de identidade nacional, já não é mais sustentável; a identidade coletiva não existe mais, só é utilizada em uma incessante busca que gera uma ainda maior fragmentação de açôes, dando-se de forma brutal, retalhada com a pregaçáo de todo tipo de guerra. No livro, esse exemplo vem da França, mas não é difícil nos aproximarmos dos atuais slogans brasileiros, ou mesmo de outras partes do mundo, pois vivemos politicamente essa onda de tornar o país grande novamente, em claras inspiraçôes estadunidenses aliadas a uma nostalgia unificadora ficcional.

Desses movimentos fragmentadores, a partir de uma situação política real, podese surgir uma inteligência, uma sensibilidade, uma determinação. Para essa análise, 
o autor traz o movimento de estudantes que ocorreu na primavera de 2006 na França, a chamada cortège de tête, iniciada pelos estudantes do ensino médio e, em seguida, por todo tipo de jovens que desertaram do que se chama-se "cadáver social", fugindo das formas de expressôes tradicionais, indo além de uma marcha uniforme de sindicalizados ou do cerco da polícia.

Essa narrativa que traz conversas com movimentos, revoltas e insurreiçóes, já estava presente na publicação anterior do próprio comitê invisível "Aos nossos amigos - Crise e insurreição" (COMITÊ INVISÍVEL, 2016), sendo um ambiente já conhecido de discussão do comitê, que retoma aqui muitas das discussôes que foram levantadas naquele momento, sendo uma pertinente revisita. Não se mantém, entretanto, nos mesmos campos de discussão, partindo para outros terrenos que estão relacionados a elementos na cena política atual como a vontade de poder, contenção e uniformização. É a partir desses elementos que a ideia do direito como garantia da exceção ganha corpo, através da construção de direitos para o cidadão e para seu inimigo, que pode estar espacialmente longe ou dentro do próprio país. Tem como exemplo as Filipinas, com os inimigos sendo os traficantes, e a "eficácia" da guerra às drogas, que se estima pela contagem de corpos dos "traficantes" mortos.

Nessa paradoxal incansável criação de leis repousa o fato do quáo insignificante estas se tornaram; segundo os autores, acabam por enterrar junto com elas o já cadavérico Estado de direito e as garantias jurídicas. Dessa morte em vida do Estado de direito é que surge a proposta de apreender as coisas de outro modo, percebendo que quem faz as leis não as respeita, que os propagadores da moral do trabalho possuem empregos fictícios e que apelar para a justiça é, como cita o livro, pedir para um ogro cuidar de suas crianças.

É neste cenário exposto no texto que surgem as opçóes, se pode nadar contra a corrente ou agir a partir dela para entender como fazer. Quando seguimos pela segunda via, devemos agir de modo que não se caia em buscas políticas incessantes pela unidade e nostalgia, compreendendo que não somos um bloco de personalidade, pois é aí que nos capturam, impondo sua própria unidade nessa fragmentação com a promessa de conectar todo o mundo, ao mesmo tempo em que nos isolamos cada vez mais do real (as redes sociais fazem isso efetivamente), imobilizando corpos. Daí a necessidade de organizar para o contato real.

No capítulo seguinte, "Morte à política", a discussão segue para a não linearidade e homogeneidade histórica da política na França, onde cada construção de proposta 
de política herda algo da construção anterior, sempre havendo degeneração das decisóes centrais do Estado até suas ramificaçóes. Diante disso, a proposta é fazer outra coisa que não seja a política.

Há o exemplo do nuit débout, movimento de março de 2016 na França que surgiu devido a alteraçóes nas leis trabalhistas, que foi espaço de vários encontros, que a partir do conflito iniciaram uma discussão em todo o país, ampliando sua compreensão de apenas um movimento social. Porém mesmo dentro da nuit débout operava o não dito, aquilo não que aparece nas falas formais ou instituídas. Por mais que houvesse a potência do movimento, as tentativas de controle através da microburocracia mantinham-se com as estratégias que estavam se desenvolvendo em um lugar distante, mostrando que horizontalidade, democracia participativa e inteligência coletiva funcionam mais como meios de controle dentro do próprio movimento, clarificando a miséria do assembleísmo de modo prático.

Daí que vem a mentira da política que muitos autores e pessoas situam de um lado, e do outro, a vida. Esta separação entre a palavra e entre o que é vivido gera uma intriga e um paradoxo entre ódio e política. A partir daí, os autores defendem que a política deveria ter continuado a ser um adjetivo, e não uma substância, pois tudo que é político envolve encontros, percepções e sensibilidades.

No capítulo seguinte, "Fim do trabalho vida mágica", há a denúncia sobre o fim da sociedade salarial, pois para a economia somos cada vez mais excedentes em um mundo onde tudo se automatiza, e mesmo assim todos os espectros políticos mantêm a promessa do pleno emprego. Quando se inventou o salário, foi permitido aos homens se iludirem a respeito do sentido da vida, colocando o sentido desta em fazer carreiras até se aposentar e então morrer, liberando-os do pesado fardo da existência. Com essa implosão da sociedade salarial, há o risco de o homem cair em questóes existenciais e acabar por levá-las a sério. Então, a fim de prevenir isso, até mesmo o lazer é cooptado atualmente; somos consumidores e trabalhadores até nesse momento.

O salto que o capitalismo causou para além do salário pode ser visto pelo que é chamado de "uberização do mundo", uma diminuição de trabalho e aumento da mediação de dinheiro para tudo; a tecnologia trata de ocupar e valorizar tudo o que o salário não consegue. Segundo os autores, é isso que o capitalismo faz; ele não é sobre o que se pode vender, mas sim sobre quais novos mercados se podem criar. Desta discussão, nos é apresentada a "teoria do morto de fome", também chamada de "teoria do capital humano", segundo a qual o homem não possui algo para 
alienar, mas é o próprio agregado, sendo produtor, produto e vendedor, que para existir socialmente necessita da medição como regra.

Isso invade nossa subjetividade com a necessidade de se valorizar o tempo todo, a eterna angústia de se estar fazendo algo ou estar com alguém, ao mesmo tempo que você está renunciando outras situaçôes e outras pessoas com nossos smartphones, não nos deixando esquecer isto. Contudo, todo ser é imensurável, e aí que devemos nos ater; as mensurações escapam a nossa existência. Assim, sair da economia é saltar deste plano de realidade, visto que a economia faz todas as relaçóes parecerem hostis. Portanto, defende-se que só podemos recorrer às estruturas econômicas se for para perfurá-las, e que a única medida do estado de crise do capital é o grau de organização das forças que pretendem destruí-lo.

Desta já abordada busca da unidade, aliada a nostalgia e organização da economia, a ordem social em si perde seu crédito e nesse momento emerge a polícia atual, como o título do capítulo seguinte não nos deixa esquecer: "Todo mundo odeia a polícia". A ordem falida tem uma atividade principal: a manutenção dessa ordem, visto que toda manifestação só tem sua ordem garantida pela violência, pois a ficção chamada "ordem" precisa se manter.

Na França, a polícia foi concebida nos séculos XVII e XVIII tanto para tratar do habitat urbano quanto para prender bandidos. A diferenciação para com a atualidade se dá principalmente quando entendemos que a polícia pode agir como um meio ou como um fim. Atualmente ela é um meio, é a efetivação de um estado de exceção tendo permissão para matar, bater e violar, demonstrando que o legal não é real.

Nessa invasão, ela atua também nos afetos provocando uma divisão entre quem tem excelentes motivos para a detestar e a massa amedrontada que a abraça (às vezes literalmente, como visto em vários autointitulados "cidadãos de bem") a causa dos policiais. No caso da polícia francesa, ela compreendeu que seu modo de agir como meio é uma condição para a manutenção do governo; contudo, ainda permanece velada se compararmos a outros locais, como a Rússia, onde após a polícia e o serviço secreto tomarem o poder, a relação da polícia e política é íntima e explícita.

Partindo disso, uma destituição da polícia é possível através da retirada de sua legitimidade através da política, com a desorganização de quadros e desconstrução de sua imagem/ação de potência, de modo que ela perca sua utilidade, não sendo mais um meio útil. Cabe ressaltar que, a partir desse ponto, a luta, a resistência, serão sempre criminais, pois tudo nelas se tornou criminalizável, e isso é algo a se 
manter em mente, pois quando se propóe o estabelecimento em rede, se deve buscar apoio nas citadas amizades e cumplicidades inesperadas.

Em seu último capítulo, "Para que segue o mundo", deixa-se claro que todos os que oferecem uma solução para os problemas enfrentados no presente são parte do problema, e justamente por isso as ideias que são apresentadas no livro não propõem soluçôes vendáveis. Como a própria ideia-título do livro, lembra-se que "destituir" em latim é também "decepcionar", e quem buscar no livro uma solução pronta não irá recebê-la; no entanto, receberá um convite para a busca das inúmeras possibilidades que existem além daquilo que nos é dado todos os dias.

Nada do que capitalismo ou comunismo oferece atualmente consegue fugir dessas máscaras de soluçooes objetivas, e mesmo que algumas saídas sejam apresentadas, cada vez que entramos em contato com a sociedade, nos tornamos cúmplices, somos cooptados, contraímos um pouco de cada vício, seja o da exploração, do saque ou da destruição das condiçôes de existência na terra. Nesse contato, temos apenas dois caminhos (também chamados de crimes): o de participar ou o de desertar. A partir daí, se retoma a ideia do comunismo, o qual no século passado foi colocado como algo social, estritamente humano, e que se mantém nessa questão até hoje. $\mathrm{O}$ comunismo da modernidade, contudo, não conseguiu abarcar vários tipos de pessoas, de nômades, camponeses, os "selvagens", tendo eles como obstáculos isolados de seu mundo.

O que há de se considerar é que as experiências de comunidade não podem ser negadas; sem ela morremos. Não é por coincidência que após anos de pregação para um individualismo publicitário do capitalismo, ele recorra agora à promessa de "comunidade" para se manter, com seus aplicativos de encontro, redes sociais e tecnologias de comunicação. Enquanto isso, o livro traz os colóquios de marxistas para discutir o comunismo, que parecem ser feitos justamente para que permaneça apenas uma ideia e que não se mergulhe na vida.

É da falsa antinomia criada no século passado pela economia, que após associar comunismo a catástrofe, massacre, ditadura e genocídio, levou anarquistas e socialistas a discutir o indivíduo-sociedade. Ela, no entanto, é falsa; não há na vida indivíduos com propriedades, mas sim indivíduos com vínculos, agenciamentos e afetos. $\mathrm{O}$ deslocamento que surge com o comunismo deve ser entendido não como uma organização econômica da sociedade, mas como a destituição da economia, de modo que nos desprendamos da imagem criada desde Hobbes, que nos faz ver unidades, 
instituições fechadas, quando o que há na realidade são vínculos, de modo que entendamos a condiçáo do capitalismo dada em toda essa anestesia de sensibilidades que vivemos hoje, onde o sofrimento para tentar sermos indivíduos se mantém.

Aí que é o lugar do comunismo, tomar os seres pelo seu interior considerando a pluralidade da vida; essa continuidade de fragmentos que nos agencia entre os corpos, a fim de entender que se o comunismo tem a ver com o fato de se organizar coletiva, material e politicamente, isso se dará na medida exata que significa também organizar-se singular, existencial e sensivelmente. Assim, a proposta que fica no livro é desertar desse plano do individual e da sociedade, renunciando aos coletivos, e tudo que traz a exterioridade de alguém em relação a si mesmo, ao mundo e aos outros, com a verdadeira questão comunista não sendo "como produzir?”, mas “como viver?”.

Em meio a essas questôes, o livro termina após caminhar por políticas e movimentos da França que nos mostram especificidades do país, mas nos afeta através de questôes vividas cotidianamente no mundo capitalista, sejam estas situadas nas nossas atuais precárias relações de trabalho, no sofrimento gerado pelo individualismo capitalista ou mesmo na falta de respostas da direita e esquerda aos problemas vividos.

O livro atua como um convite para a visibilidade das inúmeras maneiras de como habitar o mundo, nos desterritorializa ao nos deslocar por propostas ainda não pensadas em movimentos políticos em evidência, mas não abre essa discussão se prendendo à esperança de algo que algum dia possa vir. Como é enfatizado, diante de todas as cooptaçôes que sofremos todos os dias, o agir, o encontro entre corpos, os afetos, são nossos principais potenciais, e quem está na luta fica convidado a pular em um profundo mergulho na vida, no agora, não esperando soluçôes prontas e mágicas, mas a criação de vínculos e novos meios de pensar como produzir vida.

\section{Referências}

COMITÊ INVISÍVEL. A insurreição que vem. Tradução e diagramação Edições Baratas. Disponível em: <https:/dazibao.cc/wp-content/uploads/2015/11/Ainsurreic\%CC\%A7a\%CC\%83o-que-vem-CI.pdf>. Acesso em: 01 maio 2019.

. Aos nossos amigos: crise e insurreição. Tradução Ediçôes Antipáticas. São Paulo: N-1 Ediçōes, 2016. 